\title{
Assessment of F/HN-Pseudotyped Lentivirus as a Clinically Relevant Vector for Lung Gene Therapy
}

\author{
Uta Griesenbach 1,2, Makoto Inoue ${ }^{3}$, Cuixiang Meng1,2, Raymond Farley 1,2, Mario Chan ${ }^{1,2}$, \\ Nikki K. Newman ${ }^{1,2}$, Andrea Brum ${ }^{1,2}$, Jun You ${ }^{3}$, Angela Kerton ${ }^{4}$, Amelia Shoemark ${ }^{5}$, \\ A. Christopher Boyd 2,6, Jane C. Davies 1,2, Tracy E. Higgins ${ }^{1,2}$, Deborah R. Gill2,7, Stephen C. Hyde ${ }^{2,7}$, \\ J. Alastair Innes 2,6, David J. Porteous2,6, Mamoru Hasegawa ${ }^{3}$, and Eric W. F. W. Alton ${ }^{1,2}$
}

\begin{abstract}
${ }^{1}$ Department of Gene Therapy and ${ }^{4}$ Central Biomedical Services, Imperial College London, London, United Kingdom; ${ }^{2}$ The United Kingdom Cystic Fibrosis Gene Therapy Consortium, London, United Kingdom; ${ }^{3}$ DNAVEC Corporation, Tsukuba, Japan; ${ }^{5}$ Paediatric Department, Royal Brompton Hospital, London, United Kingdom; ${ }^{6}$ Medical Genetics Section, Centre for Molecular Medicine, MRC Institute of Genetics and Molecular Medicine, University of Edinburgh, Western General Hospital, Edinburgh, United Kingdom; and ${ }^{7}$ Gene Medicine Group, Nuffield Department of Clinical Laboratory Sciences, University of Oxford, John Radcliffe Hospital, Oxford, United Kingdom
\end{abstract}

\begin{abstract}
Rationale: Ongoing efforts to improve pulmonary gene transfer thereby enabling gene therapy for the treatment of lung diseases, such as cystic fibrosis (CF), has led to the assessment of a lentiviral vector (simian immunodeficiency virus [SIV]) pseudotyped with the Sendai virus envelope proteins $\mathrm{F}$ and $\mathrm{HN}$.

Objectives: To place this vector onto a translational pathway to the clinic by addressing some key milestones that have to be achieved. Methods: F/HN-SIV transduction efficiency, duration of expression, and toxicity were assessed in mice. In addition, F/HN-SIV was assessed in differentiated human air-liquid interface cultures, primary human nasal epithelial cells, and human and sheep lung slices. Measurements and Main Results: A single dose produces lung expression for the lifetime of the mouse ( $\sim 2 \mathrm{yr})$. Only brief contact time is needed to achieve transduction. Repeated daily administration leads to a dose-related increase in gene expression. Repeated monthly administration to mouse lower airways is feasible without loss of gene expression. There is no evidence of chronic toxicity during a 2-year study period. F/HN-SIV leads to persistent gene expression in human differentiated airway cultures and human lung slices and transduces freshly obtained primary human airway epithelial cells.

Conclusions: The data support F/HN-pseudotyped SIV as a promising vector for pulmonary gene therapy for several diseases including CF. We are now undertaking the necessary refinements to progress this vector into clinical trials.
\end{abstract}

Keywords: lentivirus; cystic fibrosis; gene therapy; lung; gene transfer

Gene transfer to the airway epithelium has been more difficult than originally anticipated, largely because of significant extracellular and intracellular barriers in the lung (1). In general, viral vectors are more adapted to overcoming these barriers than nonviral gene transfer agents. Viral vectors that have a natural tropism for the airway epithelium, such as those derived from adenovirus, adenoassociated virus, and Sendai virus ( $\mathrm{SeV}$ ), have been evaluated for cystic fibrosis (CF) gene therapy. SeV vector, in particular, leads to $\log$ orders higher gene expression than nonviral formulation when applied to the apical surface of airway epithelial cells $(2,3)$. However, gene expression is transient and repeated administration

(Received in original form June 14, 2012; accepted in final form August 21, 2012)

Supported in part by the Cystic Fibrosis Trust; the Dr. Benjamin Angel Senior Fellowship (U.G.); the NIHR Respiratory Disease Biomedical Research Unit at the Royal Brompton and Harefield NHS Foundation Trust; and Imperial College London.

Correspondence and requests for reprints should be addressed to Eric W. F. W. Alton, M.D., Department of Gene Therapy, Imperial College at the National Heart and Lung Institute, Manresa Road, London SW3 6LR, UK. E-mail: e.alton@imperial.ac.uk

This article has an online supplement, which is accessible from this issue's table of contents at www.atsjournals.org

Am J Respir Crit Care Med Vol 186, Iss. 9, pp 846-856, Nov 1, 2012

Copyright $\odot 2012$ by the American Thoracic Society

Originally Published in Press as DOI: 10.1164/rccm.201206-1056OC on September 6, 2012 Internet address: www.atsjournals.org

\section{AT A GLANCE COMMENTARY}

Scientific Knowledge on the Subject

Gene transfer to the airway epithelium is more difficult than originally anticipated. Until now viral gene transfer agents have not been useful for the treatment of chronic lung disease, such cystic fibrosis (CF), because of immunogenicity, which prevents successful repeat administration. Lentivirus-based vectors are a notable exception.

\section{What This Study Adds to the Field}

Moving novel therapies to the clinic requires that relevant evidence for safety and efficacy is gathered in appropriate models. Here, we provide a body of supportive evidence for F/HN-pseudotyped simian immunodeficiency virus as a potential gene transfer agent for $\mathrm{CF}$ including lifetime gene expression and efficient repeat administration in mouse lung, lack of chronic toxicity, and persistent gene expression in human ex vivo models.

is inefficient $(4,5)$. These vectors are, therefore, unlikely to solve the challenge of life-long gene therapy treatment for CF.

Lentiviral vectors are commonly pseudotyped with the Gglycoprotein from the vesicular stomatitis virus (VSV-G) allowing for a broad tissue tropism. However, VSV-G-pseudotyped vectors are comparatively inefficient at transducing airway epithelial cells and require the addition of tight junction openers, such as lysophosphatidylcholine, to allow virus entry into airway cells $(6,7)$. Several groups have attempted to further improve lentiviral vector uptake into airway epithelium by changing the viral envelope proteins. Glycoproteins from Ebola or Marburg virus that naturally transfect airway epithelial cells by the apical membrane showed early promise (8), but have more recently been superseded by viral vectors pseudotyped with the influenza M2 envelope glycoprotein (9), baculovirus protein GP64 (10), or the SeV-derived F and HN envelope proteins $(11,12)$.

The F/HN-pseudotyped simian immunodeficiency viral vector $(\mathrm{F} / \mathrm{HN}-\mathrm{SIV})$ transduces rodent airway epithelial cells in vitro (12). Recently, we have shown that F/HN-SIV leads to persistent expression in the mouse nose $(>1 \mathrm{yr})$ importantly allowing for monthly repeat administration without significant loss of efficacy (11). It is currently unclear whether the prolonged expression is caused by vector integration into pulmonary stem or progenitor cells, or by the long life-span of airway epithelial cells, which as recently reported may have a half-life of up to 17 months (13). It is also unclear how on repeated administration 
the viral vector evades the immune system, although interestingly liposomes that contain $\mathrm{SeV}$ proteins (HVJ-liposome) can also be repeatedly administered (14). This feature, and the efficient and prolonged expression profile and the ability to administer through the apical surface of the respiratory epithelium without preconditioning, makes the vector an attractive candidate for treating $\mathrm{CF}$, which is a chronic disease and requires lifelong correction of the genetic defect in airway epithelial cells.

Here, we have further developed the F and HN-pseudotyped SIV toward clinical evaluation. We show that repeated administration to the mouse lower airways is feasible. We also confirm the long-term safety profile of this viral vector and show that it transduces the relevant human airway epithelial cells required for $\mathrm{CF}$ gene therapy.

\section{METHODS}

\section{Viral Vector Production}

Purified and concentrated F/HN-SIV expressing firefly luciferase $(\mathrm{F} / \mathrm{HN}$ SIV-Lux) or enhanced green fluorescent protein (F/HN-SIV-GFP) under the transcriptional control of the cytomegalovirus (CMV) enhancer/ promoter were prepared and titrated as previously described (11) (see online supplement for further details).

\section{Mouse Lung Transfection}

Female C57BL/6N mice (6-8 wk old) were used (see online supplement). A $100-\mu l$ viral vector in Dulbecco's phosphate-buffered saline (D-PBS) was administered to the mouse nose and "sniffed" into the lung as previously described (15) (see RESULTS and FIGURES for details about vector titers used) and gene expression quantified (see online supplement).

For the daily repeat administration experiments, groups of mice were treated over 10 days with either nine daily doses of D-PBS followed by a single dose of F/HN-SIV-Lux, five daily doses of D-PBS followed by five daily doses of F/HN-SIV-Lux, or 10 daily doses of F/HN-SIV-Lux. Gene expression was analyzed 28 days after the final F/HN-SIV-Lux administration.

For the monthly repeat administration experiments groups of mice were transduced with either one dose of F/HN-SIV-Lux (single-dose group), or two doses of F/HN-SIV-GFP (Day 0, Day 28), followed by F/HN-SIV-Lux on Day 56 (repeat-dose group). Importantly, mice receiving F/HN-SIV-Lux (single-dose group) and F/HN-SIV-Lux on Day 56 (repeat-dose group) were of similar age and were transduced at the same time. Gene expression was analyzed 28 days after F/HN-SIV-Lux administration.

\section{Toxicology}

Over the 24-month study period mice were carefully observed daily and were given a full clinical examination every 2 weeks (including palpation of the abdomen for tumors) by an experienced animal technician, and bodyweight was recorded. Histologic assessment was performed in mice that showed signs of illness throughout the study period. In addition, lungs from asymptomatic mice culled at the end of the 24-month study period were also analyzed (see online supplement).

\section{Histologic Assessment of GFP Expression}

Mouse lungs were transduced with F/HN-SIV-GFP $\left(10^{8} \mathrm{TU} /\right.$ mouse in $100 \mu \mathrm{l})$ by nasal sniffing. Animals receiving D-PBS only were used as negative controls ( $\mathrm{n}=4$ per group). One month after transduction animals were culled and GFP expression was assessed in lung tissue (see online supplement).

\section{Gene Transfer into Relevant Preclinical Model}

Gene transfer into human air-liquid interface (ALI) cultures, human nasal brushings, and lung slices was performed as described in the online supplement.

\section{Statistical Analysis}

Analysis of variance followed by a Bonferroni post hoc test or KruskalWallis test followed by Dunn multiple comparison post hoc test was performed for multiple group comparison after assessing parametric and nonparametric data distribution with the Kolmogorov-Smirnov normality test, respectively. An independent Student $t$ test or a Mann-Whitney test was performed for two-group parametric and nonparametric data as appropriate. Pearson correlation was performed for parametric data. All analyses were performed using GraphPad Prism4 (GraphPad Software, Inc., La Jolla, CA) and the null hypothesis was rejected at $P$ less than 0.05 .

\section{RESULTS}

\section{Gene Expression in Mouse Lung Persists and Is Stable}

We first assessed if F/HN-SIV produced measurable levels of luciferase in murine lower airways (lungs), and if this expression was dose-related. Mice were transduced with F/HN-SIV-Lux $\left(10^{7}\right.$ or $10^{8} \mathrm{TU} /$ mouse in $100 \mu$ l total volume) by nasal sniffing $(\mathrm{n}=8$ per group) or received D-PBS $(\mathrm{n}=8)$. Two days after transduction mice were culled and luciferase expression quantified in lung homogenates. Luciferase expression was detectable and doserelated $\left(10^{7} \mathrm{TU} / \mathrm{mouse}, 2 \pm 0.3\right.$ relative light units [RLU])/mg protein; $10^{8} \mathrm{TU} / \mathrm{mouse}, 27 \pm 6.4 \mathrm{RLU} / \mathrm{mg}$ protein, $P<0.01$; D-PBS, $0.01 \pm 0.03 \mathrm{RLU} / \mathrm{mg}$ ). However, gene expression was also production batch-related (see online supplement).

We next assessed if expression in mouse lungs persisted. Mice were transduced with F/HN-SIV-Lux $\left(5 \times 10^{8} \mathrm{TU} /\right.$ mouse in $100 \mu$ l total volume) by nasal sniffing $(n=8$ in two independent experiments) or received D-PBS (negative controls, $n=6$ ) and luciferase expression was quantified using in vivo bioluminescence imaging (BLI) at regular intervals for up to 22 months. Luciferase-mediated photon emission was detectable in all treated mice 2 months after transduction (SIV, 362,660 $\pm 63,922$ photons $/ \mathrm{s} / \mathrm{cm}^{2}, \mathrm{n}=8$; D-PBS, $66,535 \pm 4,868$ photons $/ \mathrm{s} / \mathrm{cm}^{2}, \mathrm{n}=$ 6 ; $P<0.005)$. Seven out of eight mice survived for 16 months and four out of the eight mice survived until termination of the experiment at 22 months. All of the SIV transduced mice had detectable luciferase expression at all time points. Photon emission increased modestly, but significantly $(P<0.005)$, over time (SIV at $2 \mathrm{mo}, 381,123 \pm 70,665$ photons $/ \mathrm{s} / \mathrm{cm}^{2}$; at 16 months, $543,156 \pm 65,234$ photons $/ \mathrm{s} / \mathrm{cm}^{2} ; \mathrm{n}=7$ mice with data for both timepoints). This was maintained at 22 months $(2 \mathrm{mo}, 367,485 \pm 115,923$ photons $/ \mathrm{s} / \mathrm{cm}^{2} ; 22$ months, $1,407,000 \pm 435,790$ photons $/ \mathrm{s} / \mathrm{cm}^{2} ; \mathrm{n}=4$ mice with data for both time-points). In contrast, photon emission in D-PBS-treated mice remained stable over the same time period (Figures $1 \mathrm{~A}$ and $1 \mathrm{~B})$.

An increase in photon emission may indicate an increase in luciferase expression potentially caused by an increase in the number of luciferase-expressing cells over time or may be a peculiarity of BLI. We therefore repeated the experiment comparing BLI with post-mortem quantification of luciferase expression in lung tissue homogenates in the same animals. Mice were transduced with F/HN-SIV $\left(10^{7}\right.$ TU/mouse, $\mathrm{n}=8-12$ per time-point $)$ and at regular intervals over a 24-month period (for technical reasons BLI could only be performed between 6 and 24 months after gene transfer) and post-mortem quantification of luciferase expression in lung tissue homogenate was performed in cohorts of mice. Similar to results described previously photon emission significantly $(P<0.001)$ increased over the study period $\left(B L I\right.$ at $6 \mathrm{mo}, 87,915 \pm 8,871$ photons $/ \mathrm{s} / \mathrm{cm}^{2} ;$ BLI at $24 \mathrm{mo}$, $310,334 \pm 36,274$ photons $/ \mathrm{s} / \mathrm{cm}^{2}$ ) (Figure $1 \mathrm{C}$ ), whereas detectable levels of luciferase in tissue homogenate remained stable (Figure 1D). There was no correlation between in vivo photon emission and luciferase expression quantified in tissue homogenates (Spearman $r=0.205 ; P=0.11 ; \mathrm{n}=63$ paired data points from 6-24 mo). However, luciferase expression quantified in tissue homogenates correlated well with photon emission from the same animal when lungs were extracted before BLI (Figure 1E) (Spearman $r=0.75 ; P=0.01 ; \mathrm{n}=11$ paired data points at $24 \mathrm{mo}$ ), which implies that photon quenching may occur in vivo. 
A
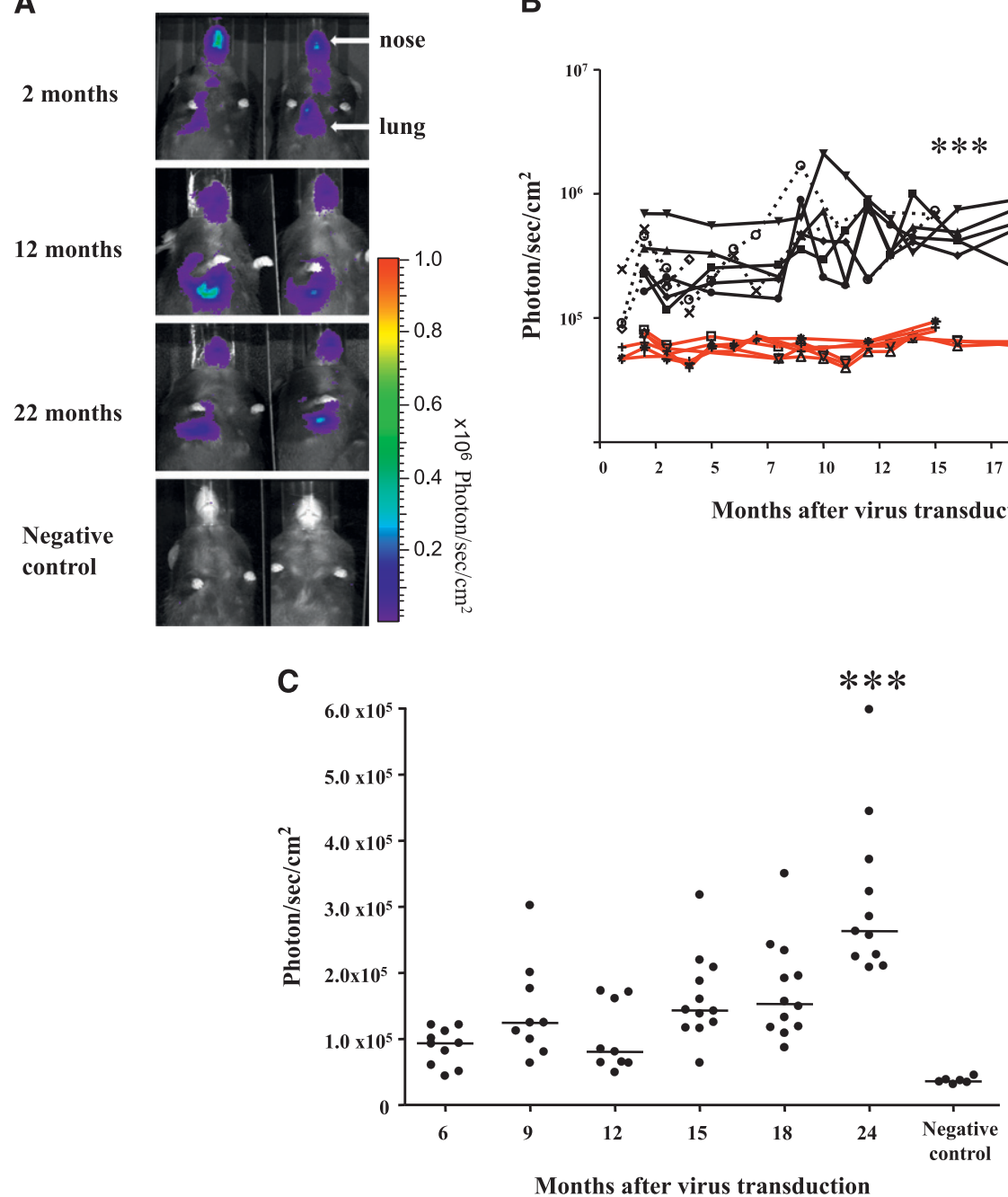

B

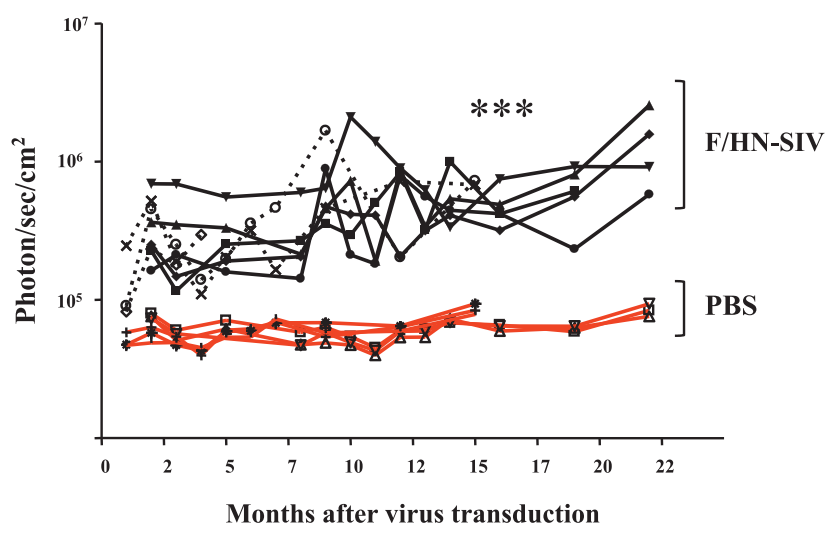

Figure 1. F/HN simian immunodeficiency virus (SIV) transduction leads to persistent gene expression in mouse lung. Mice were transduced with $\mathrm{F} / \mathrm{HN}$-SIVluciferase (Lux) $\left(5 \times 10^{8} \mathrm{TU} /\right.$ mouse) by nasal sniffing ( $n=8$ in two independent experiments) or received phosphate-buffered saline (PBS) (negative controls, $\mathrm{n}=6$ ). Lux expression was quantified using bioluminescence imaging (BLI) or in tissue homogenate at regular intervals for up to 24 months. (A) BLI 2-22 months after transduction. Representative images of two mice reaching the 22 months time point are shown. (B) Quantification of in vivo $\mathrm{BLI}$ over time (black lines, $\mathrm{n}=8$ ) or PBS (red lines, $\mathrm{n}=6$ ). Each line represents photon emission over time in one animal. Solid and dotted lines represent independent experiments. ${ }^{* * *} P<0.005$ when compared with Month 2. BLI (C) and Lux expression in lung tissue homogenate $(D)$ was repeated at regular intervals over 24 months in a third independent experiment $\left(10^{7}\right.$ $\mathrm{TU} / \mathrm{mouse},=8-12$ per timepoint). For technical reasons BLI could only be performed between 6 and 24 months after gene transfer. ${ }^{* * *} p<$ 0.005 when compared with Month 6. Quantification of

Lux expression in lung tissue homogenate was performed at regular intervals over the 24-month study period. Each dot represents one animal. Horizontal bars represent the group median. (E) Correlation between Lux expression quantified in tissue homogenates and photons emitted from extracted lungs (representative images from 11 extracted lungs are shown). Each dot represents one animal. ( $F$ ) Detection of green fluorescent protein (GFP) expression in lung after transduction with F/HN-SIV-GFP $\left(10^{8} \mathrm{TU} /\right.$ mouse). Transduced GFP-positive cells were identified using fluorescent microscopy (original magnification, $\times 20$ ). (i) PBS-treated negative control. (ii and iii) Tissue sections from F/HN-SIV-GFP-treated mice showing GFP-positive cells in airways (arrows) and alveoli. Representative images from four mice per group are shown. RLU $=$ relative light units.

Additional technical considerations relating to limitations of BLI and virus batch-to-batch variability became apparent in this study (see online supplement).

To determine what cell types were transduced in the lung we transfected mice with F/HN-SIV-GFP $\left(10^{8} \mathrm{TU} /\right.$ mouse $)$ or D-PBS ( $\mathrm{n}=4$ per group) by nasal sniffing and assessed GFP expression 1 month after transduction. GFP expression was detectable in airway epithelial cells, and also in the alveolar region (Figure 1F).

\section{F/HN-SIV Requires Only Short Contact Time to Achieve Efficient Transduction}

We compared prolonged contact time of the vector with the nasal epithelium (by perfusion) with very brief contact time (sniffing). The latter led to equally efficient transduction of the nasal epithelium as the former (Figures 2A and 2B). This suggests that a short contact time between the viral vector and the target cell may be sufficient for efficient vector uptake into the cells, of potential importance in future clinical trials.

Gene expression in the nose also persisted for 15-22 months in seven out of eight mice, but in contrast to the lung gradually declined by approximately $60 \%$ over this period (SIV Month 2, $1,309,000 \pm 316,612$ photons $/ \mathrm{s} / \mathrm{cm}^{2}$; SIV Month 15, 583,951 \pm 228,804 photons $/ \mathrm{s} / \mathrm{cm}^{2}, P<0.05, \mathrm{n}=7$ per group; D-PBS Month $15,53,021 \pm 2,325$ photons $\left./ \mathrm{s} / \mathrm{cm}^{2}, P<0.005\right)$, which may be caused by different cell types being transduced in nose and lung or different turnover rates of the cells at these two sites. Consistent with our previous data using nonviral gene transfer agents (16), intranasal administration of luciferin (the substrate for luciferase) boosted F/HN-SIV-Lux-derived photon emission in mice that were negative after intraperitoneal administration of luciferin (Figure 2C).

\section{Daily Repeat Administration to the Lung Is Feasible}

Although gene expression after a single dose of F/HN-SIV persists for the lifetime of the animal, a single dose may not be sufficient to achieve therapeutic benefit in humans. It is, for example, conceivable that the total volume required for delivery of the optimal vector titer to the human lung may be too large for a single dose and administration may have to be split into several doses to accommodate the volume. We, therefore, assessed if repeated daily 


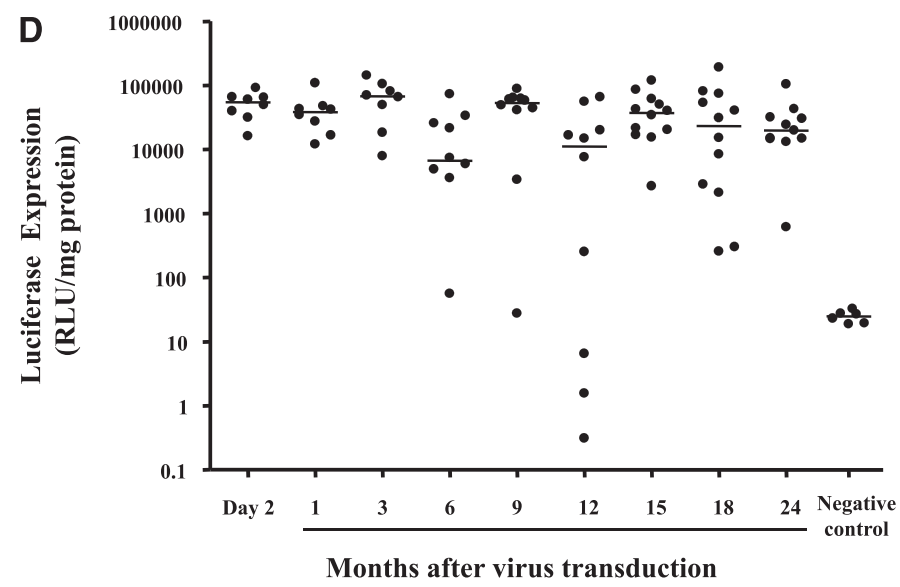

E
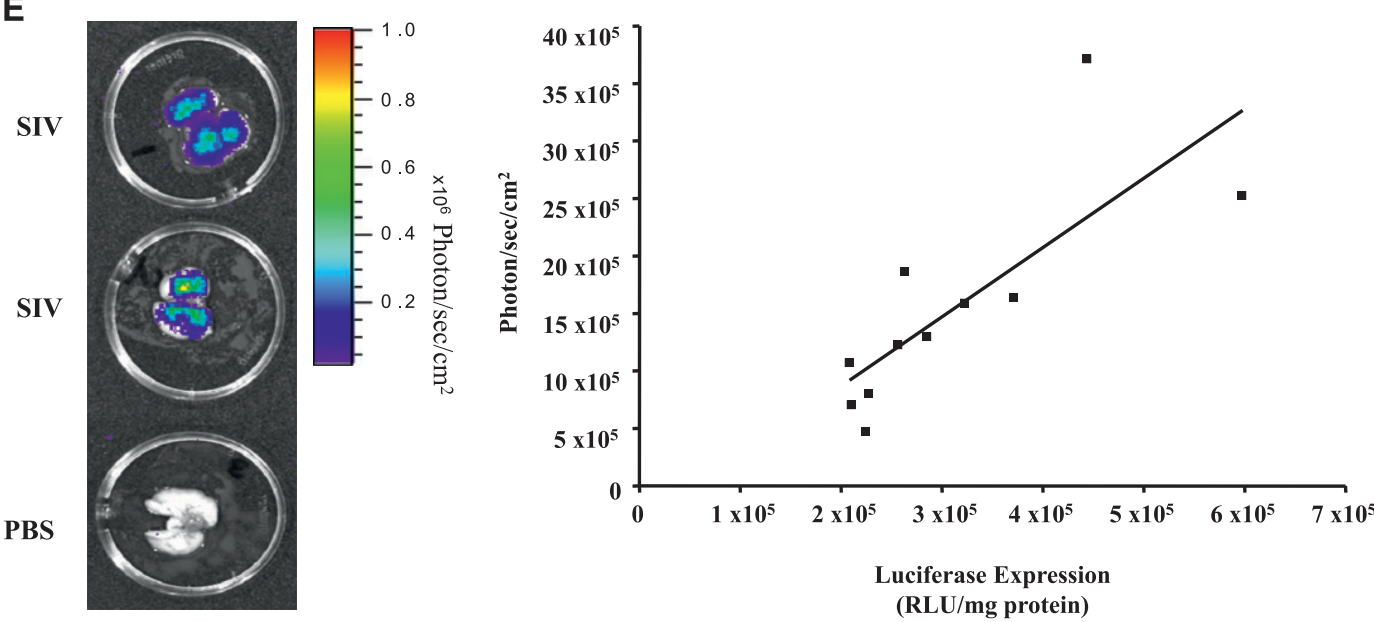

Figure 1. (Continued).

$\mathbf{F}$
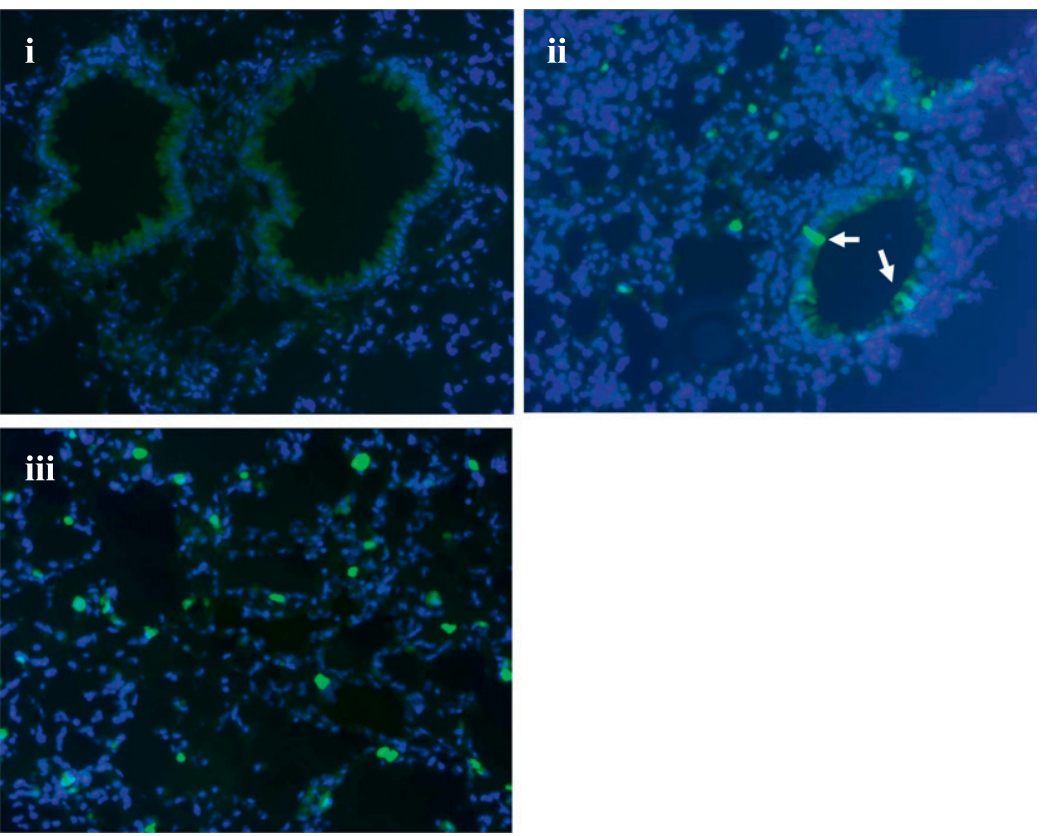

administration of the viral vector is feasible and if this leads to incrementally increased gene expression compared with a single dose. Mice ( $n=8$ per group) were treated with either $\mathrm{F} / \mathrm{HN}$ SIV-Lux daily for 10 days $\left(10^{6} \mathrm{TU} /\right.$ day in $\left.100 \mu \mathrm{l}\right)$ or with PBS $(100 \mu \mathrm{l})$ for 5 days followed by 5 days of F/HN-SIV-Lux $\left(10^{6}\right.$
TU/day) or with D-PBS for 9 days followed by 1 day of $\mathrm{F} / \mathrm{HN}$ SIV-Lux $\left(10^{6} \mathrm{TU} /\right.$ day); Lux expression was quantified 28 days after the last dose. Gene expression was significantly correlated (Pearson $r^{2}=0.61 ; P>0.0001$ ) with the number of F/HN-SIVLux doses given (Figure $3 \mathrm{~A}$ ) and indicated that daily repeat 
A

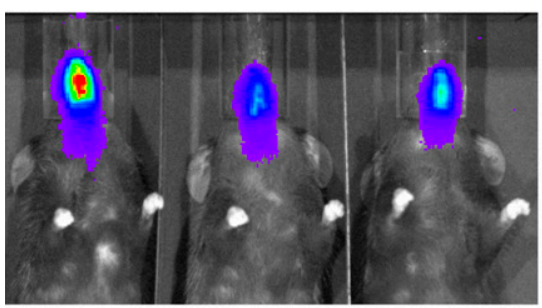

Perfusion

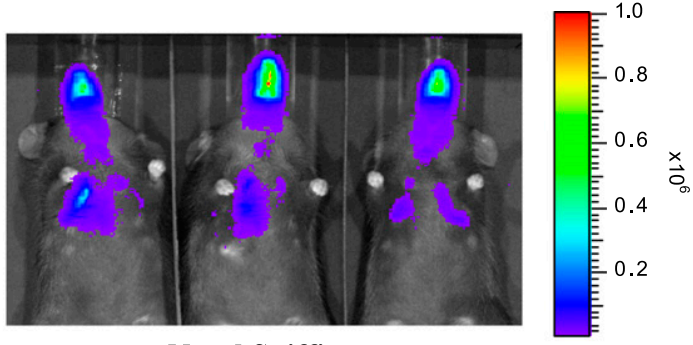

Nasal Sniffing

\section{B}

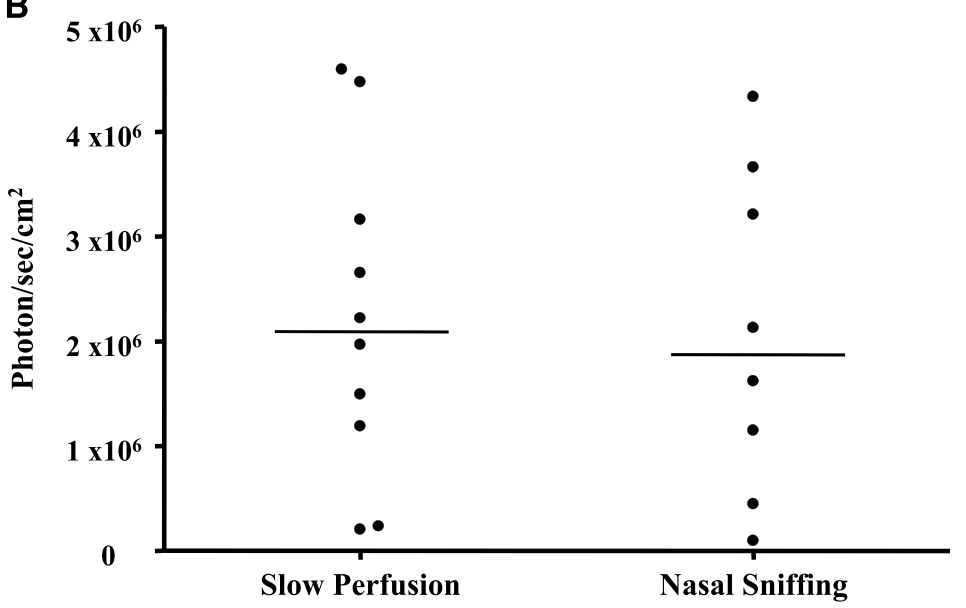

C Mouse 1

\section{Month 8}

IP

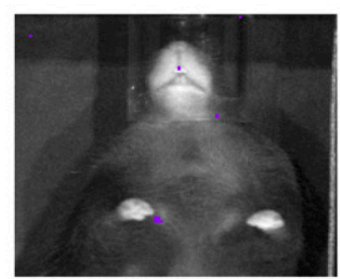

Month 10

IN

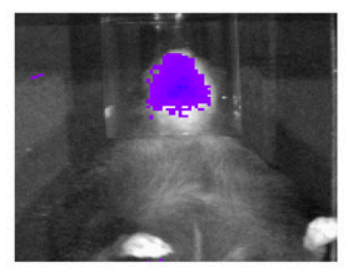

Month 14

IN

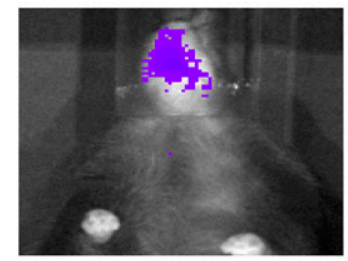

Mouse 2

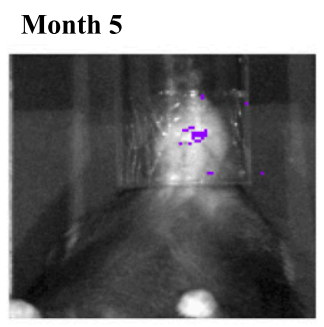

Month 6

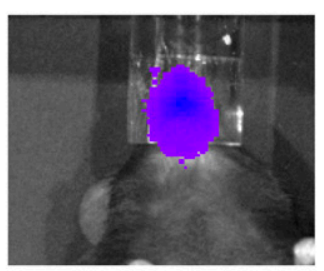

Month 23

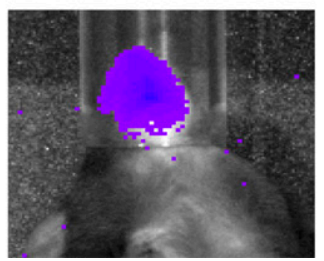

Figure 2. $\mathrm{F} / \mathrm{HN}$ simian immunodeficiency virus (SIV) requires only short contact time to achieve efficient transduction. Luciferase (Lux) expression was compared in mice receiving $\mathrm{F} /$ HN-SIV-Lux (3-4 × $10^{8} \mathrm{TU} / \mathrm{mouse}$ in $100 \mu \mathrm{l})$ by slow perfusion $(1.3 \mu \mathrm{l} / \mathrm{min}$, $\mathrm{n}=10)$ or as bolus administration by nasal sniffing $(\mathrm{n}=8)$. ( $A$ ) Bioluminescence in vivo signal in the mouse nose. Representative images of three mice are shown. (B) Quantification of in vivo bioluminescence in mouse nose after slow perfusion or nasal sniffing of the vector. Each dot represents one animal. Horizontal bars represent the group median. (C) Bioluminescence in vivo signal in mouse nose after intraperitoneal (IP) or intranasal (IN) administration of luciferin. Representative images of two of five mice are shown. Lux expression after slow perfusion of the F/HN-SIV-Lux has been published previously (11). administration is feasible and significantly increases transduction efficiency.

\section{Monthly Repeat Administration to the Lung Is Feasible}

Although a single dose of F/HN-SIV generates persistent gene expression for approximately 2 years in mice (lifetime of the animal) a single dose is unlikely sufficient to achieve clinical benefit for the lifetime of a patient with CF. Therefore, a crucial question is whether the vector can produce gene expression on repeated administration to the lung. As shown previously, daily administration was feasible, but this timeframe is unlikely to be sufficient for the development of effective immune responses to the viral vector. 


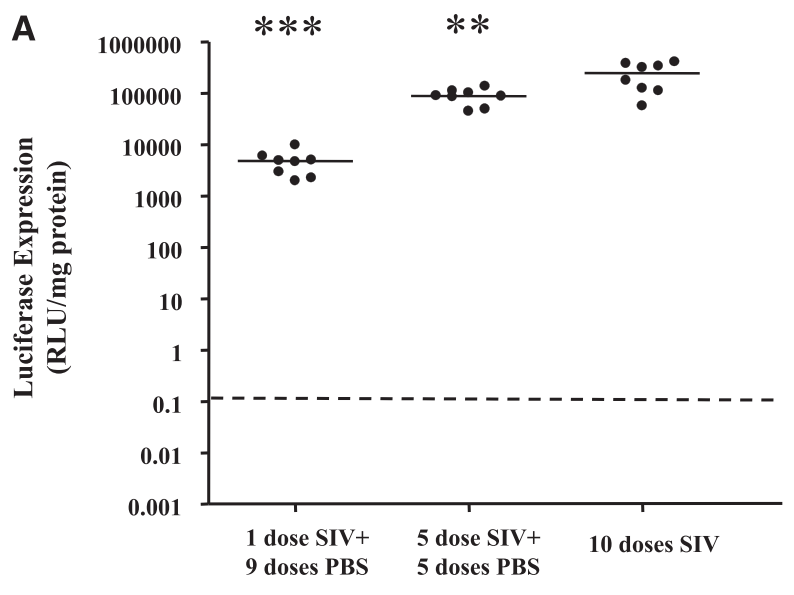

B

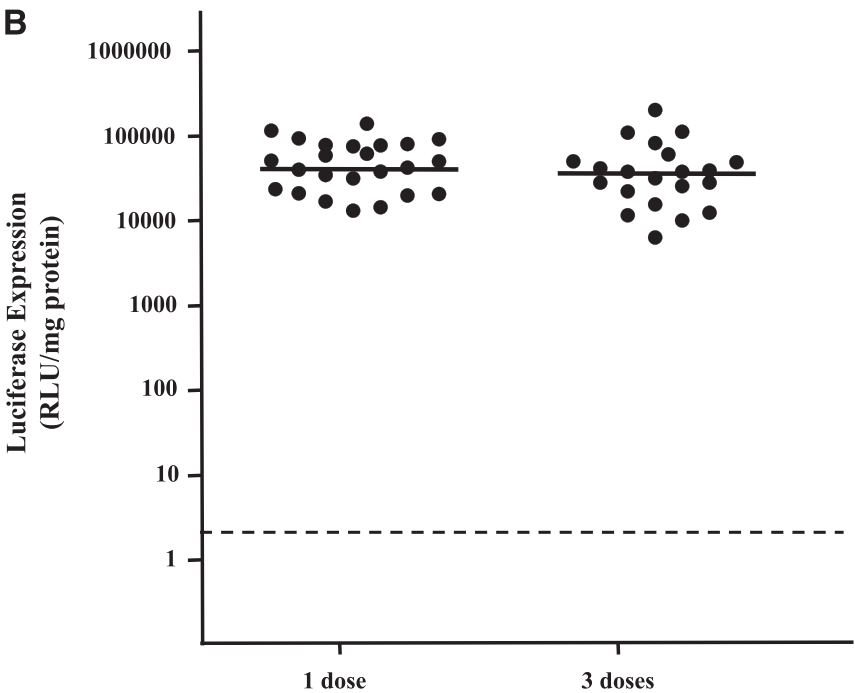

Figure 3. Daily and monthly repeat administration to the lung is feasible. (A) Daily readministration. Mice ( $\mathrm{n}=8$ per group) were treated with either $\mathrm{F} / \mathrm{HN}$ simian immunodeficiency virus (SIV) luciferase (Lux) for 10 days $\left(10^{6} \mathrm{TU} /\right.$ day) or with $\mathrm{D}$ phosphate buffered saline (PBS) for 5 days followed by 5 days of F/HN-SIV-Lux $\left(10^{6} \mathrm{TU} /\right.$ day $)$ or with D-PBS for 9 days followed by 1 day of F/HN-SIV-Lux $\left(10^{6} \mathrm{TU}\right)$. Lux expression was analyzed 28 days after F/HN-SIV-Lux administration. (B) Monthly readministration. Mice were either treated with one dose of F/HN-SIVLux (single-dose group) or two doses of F/HN-SIV-GFP (Day 0, Day 28), followed by F/HN-SIV-Lux on Day 56 (repeat-dose group). All mice receive $10^{7} \mathrm{TU} /$ dose $(\mathrm{n}=20$ per group) and gene expression was analyzed 28 days after F/HN-SIV-Lux administration. Each dot represents one animal. Horizontal bars represent the group median. Dotted line represents negative control values, ${ }^{* * *} P<0.0001$ when compared with 5 and 10 doses, $\star * P<0.01$ when compared with 10 doses. RLU $=$ relative light units.

We therefore conducted repeat administration experiments at monthly dosing intervals, a period we have shown to be sufficient for the development of an immune response to other viral vectors $(5,17)$. Mice were either treated with one dose of F/HN-SIV-Lux (single-dose group) or two doses of F/HN-SIV-GFP (Day 0, Day 28), followed by F/HN-SIV-Lux on Day 56 (repeat-dose group). All mice received $10^{7} \mathrm{TU}$ in $100 \mu \mathrm{l}$ per dose $(\mathrm{n}=20$ per group) and gene expression was analyzed 28 days after F/HN-SIV-Lux administration. All mice received only one dose of vector carrying a luciferase reporter gene to avoid interference of antiluciferase antibodies. As shown in Figure 3B luciferase expression levels after one and three doses of the viral vector were identical and at this vector titer $4 \log$ orders above background levels $(P<0.01)$.
No Evidence of Chronic Toxicity Was Seen during a Two-Year Follow-up Period

Chronic toxicity caused by insertional mutagenesis is a potential concern with this vector. Here, we compared 24-months survival of mice treated with F/HN-SIV-Lux $\left(10^{7}\right.$ TU/mouse, $n=99$ at start of the experiment) or D-PBS ( $n=48$ at start of the experiment). Mortality (Figure 4A) and weight (Table 1) in both groups was similar. We also assessed the lungs of D-PBS- or F/ HN-SIV-Lux- $\left(10^{7}\right.$ TU/mouse, $\mathrm{n}=12$ per group $)$ treated mice histologically 24 months after nasal sniffing; there were no differences in any of the key histologic markers (Figures 4B-4D). Eleven D-PBS and seven F/HN-SIV-treated mice were culled because they showed signs of illness or were found dead during the study. Histologic examination revealed a range of pathology commonly found in aging $\mathrm{C} 57 \mathrm{BL} / 6 \mathrm{~N}$ mice equally distributed between the two groups (Table 2).

\section{F/HN-SIV Transduction of Human Ex Vivo Models Is Feasible}

F/HN-SIV achieves persistent gene expression in differentiated human ALI cultures. To assess the efficiency of the viral vector in relevant human tissues we transduced human ALIs with $\mathrm{F}$ / HN-SIV-Lux at multiplicity of infection (MOI) 25 or 250 ( $\mathrm{n}=5$ per group), with D-PBS control $(n=3)$, or with GL67A, the most efficient nonviral gene transfer agent for airway epithelium. The latter was complexed with a eukaryotic expression plasmid expressing luciferase $\left(10 \mu \mathrm{g}\right.$ pCIKLux per ALI equivalent to $3 \times 10^{12}$ plasmids and an approximate MOI of $\left.7 \times 10^{6}\right)(\mathrm{n}=3)$ and luciferase expression followed using BLI for 3 months (representative images are shown in Figure 5A). F/HN-SIV-mediated expression was dose-related and persisted for at least 3 months without the loss of activity. In contrast, transfection with GL67A/ pCIKLux was only barely detectable at an early time-point (Day 2) after transfection (Figure 5B). Lipid-mediated gene transfer was associated with cell damage as indicated by the appearance of small holes in the ALIs; this was not seen with exposure of the ALIs to the lentiviral vector (data not shown).

F/HN-SIV transduces primary human pulmonary cells. We assessed if F/HN-SIV transduces primary human airway epithelial cells obtained from nasal brushings or human lung slices generated from lung resection tissue (Figure 6A). Nasal brushings were transduced with F/HN-SIV-Lux at an MOI of 25 and 250 or treated with D-PBS ( $\mathrm{n}=6$ per group) and luciferase expression was quantified 24 hours after transduction (cell viability precludes longer time scales). Luciferase expression was significantly $(P<0.005)$ increased compared with PBS control subjects (Figure 6B). These results were confirmed in an independent experiment (MOI 25, $9.7 \times 10^{6} \pm 0.9 \times 10^{6}$; MOI 250, $1.5 \times 10^{7} \pm 1.6 \times 10^{6}$; negative control subjects, $2,762 \pm 241$ $\mathrm{RLU} / \mathrm{mg}$ protein, $\mathrm{n}=4$ per group)

F/HN-SIV achieves persistent gene expression in human and sheep lung slices. Precision-cut human lung slices were transduced with F/HN-SIV-Lux $\left(2 \times 10^{7}\right.$ TU/slice $)$, or remained untransduced, and luciferase expression quantified for 14 days after transduction. Assessment of later time-points is currently not feasible because of limited tissue viability (Figure 6C). Two independent experiments were performed (see open and closed symbols in the figure) but data were pooled to allow for robust statistical analysis. Significant $(P<0.001)$ and stable gene expression was detectable for at least 14 days $(P<0.05)$ after gene transfer.

We also repeated these experiments in sheep lung slices (two independent experiments), which generally survive longer than human lung slices when cultured (unpublished data). Significant $(P<$ 0.001 to $P<0.05)$ and stable luciferase expression was detectable at all time-points for at least 26 days after transduction 
A

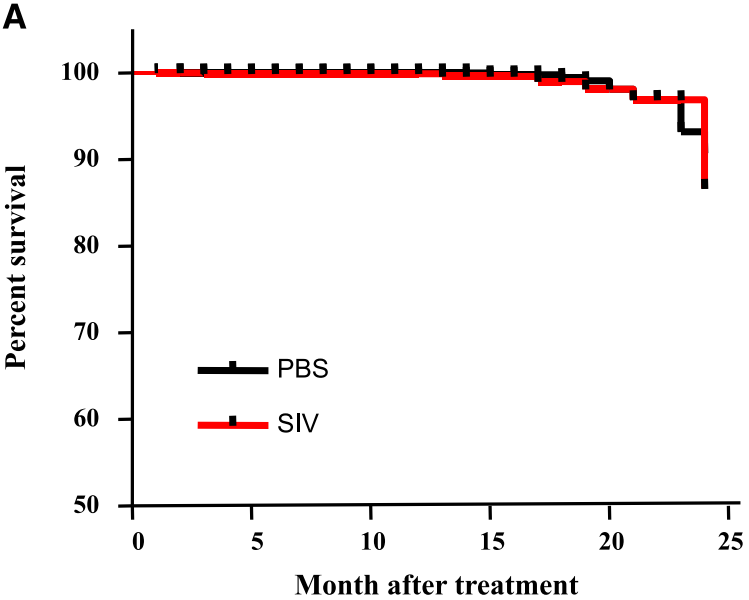

B
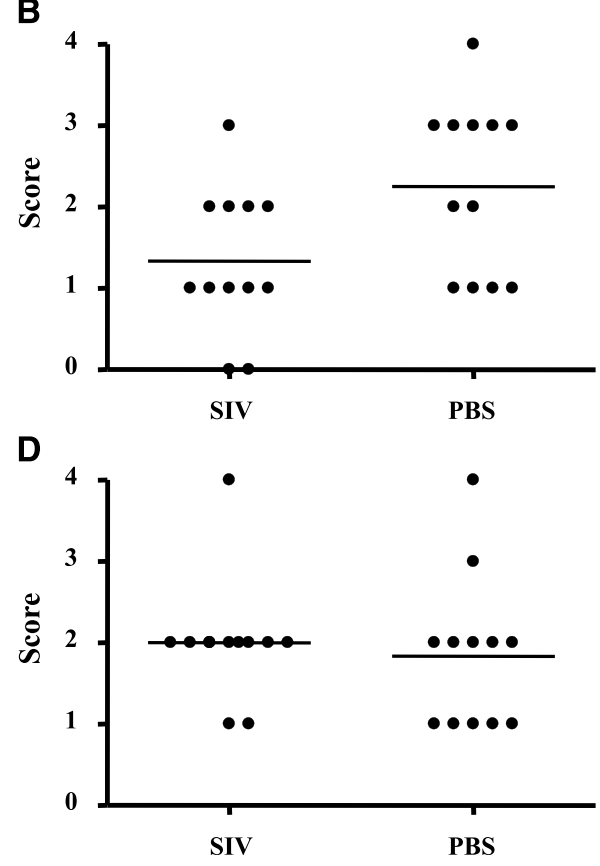

(Figure 6D). These results indicate that F/HN-SIV is able to transduce primary human and sheep pulmonary cells and provides persistent expression.

\section{DISCUSSION}

The efforts of one of our team to improve pulmonary gene transfer and enable gene therapy for the treatment of lung diseases, such as $\mathrm{CF}$, have led to the development of a lentiviral vector pseudotyped with the SeV envelope proteins F and HN (12). Moving novel therapies to the clinic requires that relevant evidence for safety and efficacy is gathered in appropriate models. Here, we begin to place this vector onto a translational pathway to the clinic and provide a body of supportive evidence for $\mathrm{F} /$ $\mathrm{HN}$-pseudotyped SIV as a potential gene transfer agent for CF. We show that (1) a single dose produces lung expression for the life-time of the mouse ( $\sim 2 \mathrm{yr}$ ); (2) only brief contact time (seconds) is needed to achieve transduction; (3) repeated daily administration leads to a dose-related increase in gene expression; (4) repeated monthly administration to mouse lower airways is feasible without loss of gene expression; (5) there is no evidence of chronic toxicity during a 2-year study period; and (6) F/HNSIV transduction generates persistent gene expression in human differentiated airway cultures and freshly obtained human lung
Figure 4. No evidence of chronic toxicity during 2-year follow-up period. (A) Twentyfour months survival of mice treated with $\mathrm{F} /$ HN simian immunodeficiency virus (SIV) luciferase (Lux) $\left(10^{7} \mathrm{TU} /\right.$ mouse, $\mathrm{n}=99$ at start of the experiment) or phosphate-buffered saline (PBS) ( $n=48$ at start of the experiment) by nasal sniffing. Comparison of lymphocytes $(B)$, edema $(C)$, and inflammation $(D)$ in mouse lung 24 months after F/HN-SIV-Lux or PBS treatment. Each dot represents one animal. Horizontal bars represent the group median. slices and transduces freshly obtained primary human airway epithelial cells.

At least two previous studies have shown that lentiviral vectormediated transduction of mouse lung leads to persistent (15 and $24 \mathrm{mo}$ ) gene expression in the murine lower airways (18, 19). However, both studies used a VSV-G-pseudotyped lentiviral vector, which almost exclusively transduces alveolar macrophages, rather than lung epithelial cells. In addition to the airway epithelium, the target for CF gene therapy, cells in the peripheral lung (a mixture of pneumocytes and macrophages) are transduced after bolus administration of the viral vector by nasal sniffing, which may lead to pooling of liquid in the

TABLE 1. MOUSE WEIGHTS 6, 15, AND 24 MONTHS AFTER LUNG TRANSDUCTION WITH F/HN-SIV-LUX OR PBS ADMINISTRATION

\begin{tabular}{lcc}
\hline Months After Treatment & PBS-treated Mice 8 $\mathrm{g}$ & SIV-treated Mice 8 g \\
\hline 6 & $24.9(0.5) \mathrm{n}=48$ & $25.4(0.3) \mathrm{n}=71$ \\
15 & $30.7(0.7) \mathrm{n}=47$ & $31.4(0.8) \mathrm{n}=35$ \\
24 & $30.1(1.4) \mathrm{n}=36$ & $29.1(1.1) \mathrm{n}=12$ \\
\hline
\end{tabular}

Definition of abbreviations: LUX = luciferase; PBS = phosphate-buffered saline; SIV = simian immunodeficiency virus.

Mean weights $( \pm$ SEM) are shown. There were no differences between PBSand SIV-treated mice. 
TABLE 2. CAUSE OF MORTALITY OF PBS- AND F/HN-SIV-TREATED MICE OVER A 24-MONTH PERIOD

\begin{tabular}{lcl}
\hline Treatment & Death (mo after treatment) & \multicolumn{1}{c}{ Diagnosis } \\
\hline PBS & 15 & Found dead \\
PBS & 18 & Lymphoma \\
PBS & 19 & Lymphoma \\
PBS & 20 & Lymphoma \\
PBS & 20 & Inconclusive \\
PBS & 21 & No pathology found \\
PBS & 21 & Lymphoma \\
PBS & 23 & No pathology found \\
PBS & 23 & Found dead \\
PBS & 23 & Lymphoma \\
PBS & 24 & Found dead \\
SIV & 3 & Peritonitis \\
SIV & 13 & Found dead \\
SIV & 17 & Found dead \\
SIV & 19 & Pancreatic tumor \\
SIV & 21 & Multiorgan inflammation \\
SIV & 24 & Found dead \\
SIV & 24 & Multifocal lymphocytic \\
& & inflammation \\
\hline
\end{tabular}

Definition of abbreviations: PBS = phosphate-buffered saline; SIV = simian immunodeficiency virus.

peripheral lung. To determine transduction efficiency of airway epithelium more accurately the viral vector needs to be administered by nebulization. Further work is now warranted to determine whether F/HN-SIV is stable in clinically approved nebulizers and that virus production can be scaled up to the extent required for clinical studies. We are currently assessing if $\mathrm{F} / \mathrm{HN}$ SIV is stable in clinically approved nebulizers and preliminary results indicate that infectivity after nebulization is retained (data not shown); and scaling up vector production to allow us to move into in vivo nebulization experiments in the near future.
Although expression levels in the lung are completely stable over the 2-year study period, those in the nasal epithelium declined by approximately $60 \%$. The latter is consistent with our previous data (11) and may relate to different cell types being transduced in the lung (airway epithelium and alveolar cells) and nose (mainly ciliated airway epithelial cells) (11) and different turnover rates of these cells at these two sites. Although, we do not have information about turnover of nasal airway epithelium, Rawlins and Hogan (13) have shown that the halflife of ciliated airway epithelial cells in the mouse trachea and lung differs (trachea, average half-life $6 \mathrm{mo}$; lung, average halflife $17 \mathrm{mo}$ ).

We have previously shown that prolongation of contact time between nonviral gene transfer agents and the airway epithelium significantly increases gene expression (20). In our previous study, we therefore slowly perfused F/HN-SIV $(1.3 \mu \mathrm{l} / \mathrm{min})$ onto the mouse nasal epithelium to maximize transduction (11). Transduction efficiency in the nasal epithelium after administration of a bolus of fluid that is rapidly (seconds) sniffed into the lung led to similar levels of photon emission. This implies that brief contact time between F/HN-SIV and the target cell may be sufficient for efficient vector uptake into the cells, which is an important factor for clinical translation. F/HN-SIV therefore mimics $\mathrm{SeV}$ (2) from which the F and HN envelope proteins were derived.

We and others have previously shown that repeated administration of lentiviral vectors to the mouse nasal epithelium is feasible $(10,11)$. To move our translational research a step closer to clinical relevance we now assessed repeat administration of the vector in the lung. Two types of repeat administration experiments were performed: daily and monthly. The former was assessed because it is conceivable that the total volume required for delivery of a specific vector titer to the human lung may be too large for a single dose and administration may have to be
A

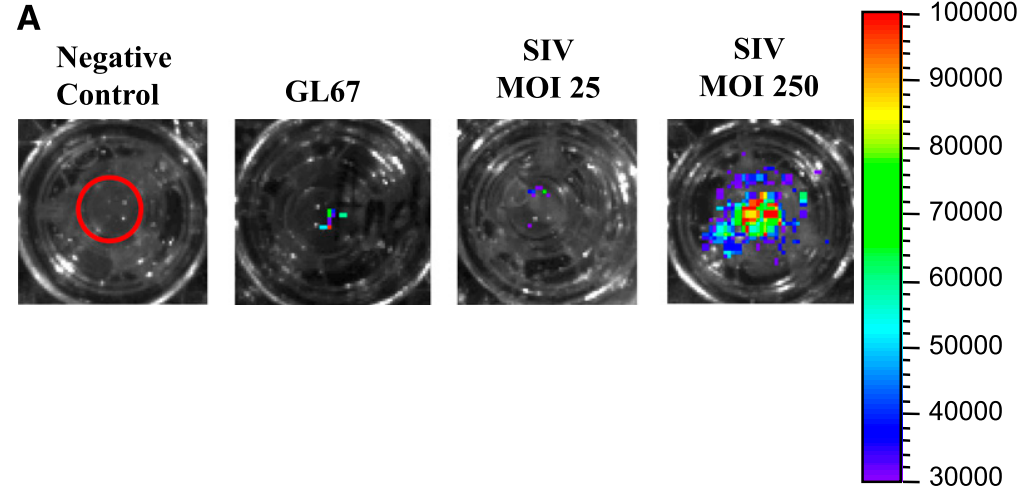

B

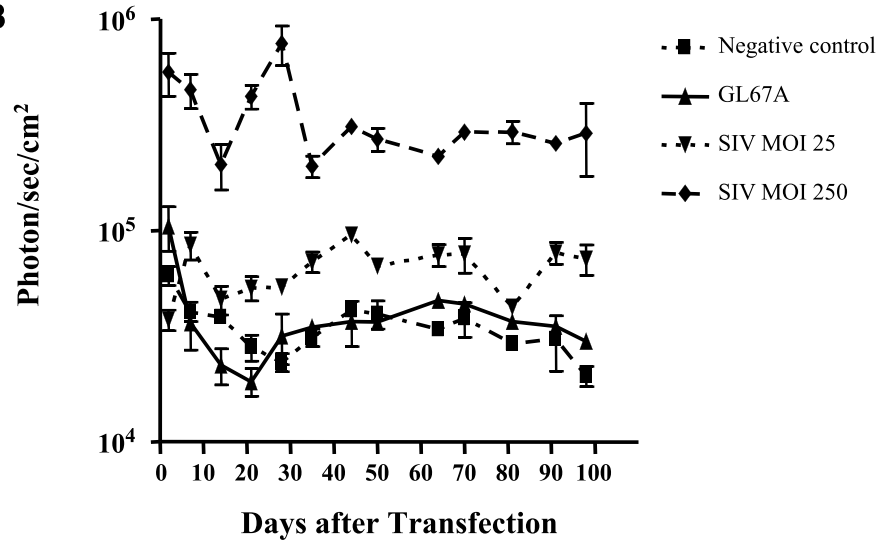

Figure 5. Persistent gene expression in differentiated airliquid interface (ALI) cultures. Differentiated human ALI cultures were transduced with $\mathrm{F} / \mathrm{HN}$ simian immunodeficiency virus (SIV) luciferase (Lux) at multiplicity of infection (MOI) 25 or 250 ( $n=5$ per group), transfected with GL67A complexed to a eukaryotic expression plasmid expressing Lux (10 $\mu \mathrm{g}$ pCIKLux per ALI equivalent to $3 \times 10^{12}$ plasmids and an approximate $\mathrm{MOI}$ of $7 \times 10^{6}$ ) $(n=3)$ or treated with phosphate-buffered saline (PBS) (negative control, $\mathrm{n}=3$ ). Lux expression was followed using bioluminescence imaging for 3 months. (A) Representative images are shown. (B) Quantification of Lux expression over 3 months. 
A
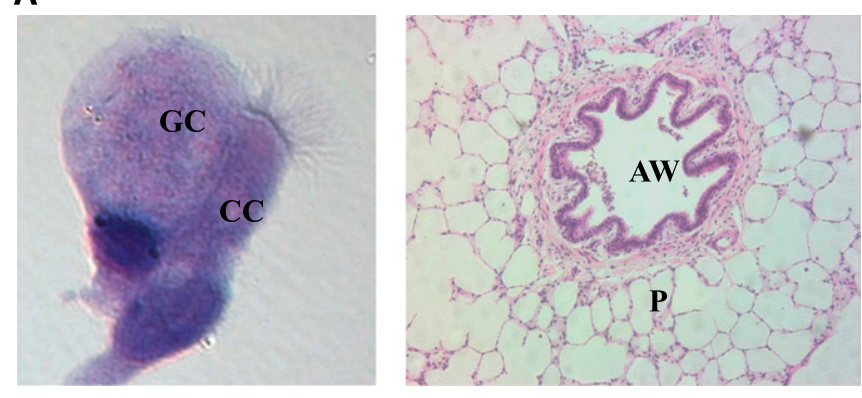

B

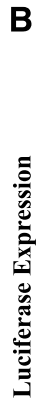

.

C

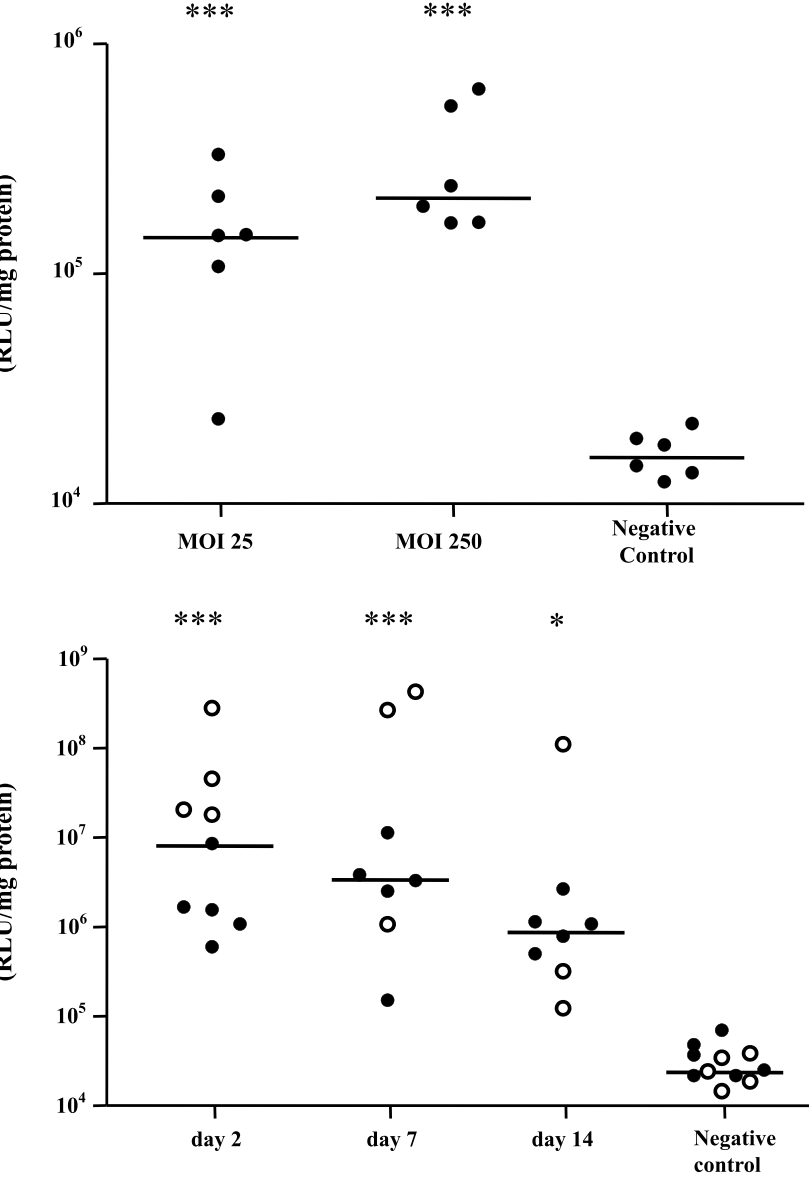

D

D

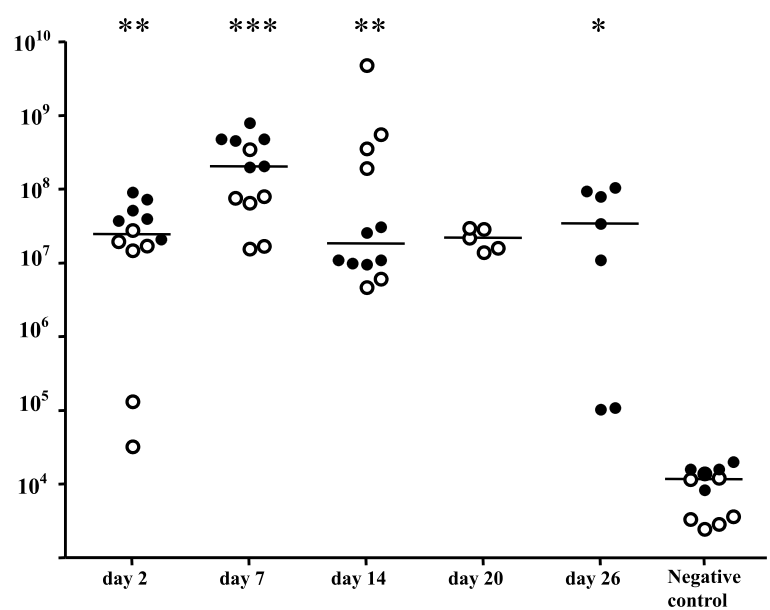

split into several doses to accommodate the volume. Here, we show that daily repeat administration is feasible and leads to a dose-related increase in gene expression. Although important, we have not yet addressed the question if "split-dose" delivery of a specific vector titer (e.g., 10 doses of $10^{7} \mathrm{TU}$ ) offers advantages over "single-dose" delivery of the same vector titer (e.g., one dose of $10^{8} \mathrm{TU}$ ), which may also be a relevant translational research question. Although efficient daily-repeat administration is encouraging, this time-frame is generally not considered to be sufficient to induce robust immune responses to the viral vector. To confirm that long-term F/HN-SIV repeat administration to the lower airways is feasible viral vector was administered monthly over a 3-month period. This dosing interval may be of clinical relevance and is also an accepted timeframe for the induction of robust immune responses. Uniquely for a viral vector (in our hands), luciferase expression levels after one and three doses were identical and more than $4 \log$ orders higher than in untransduced control mice.

Another important consideration for translational development of a gene transfer agent is safety. The occurrence of leukemia and myelodysplasia in some patients with primary immunodeficiencies after treatment with $\gamma$ retroviral vector-transduced bone marrow (21) raises concerns about the safety of integrating viral vectors. The risk of insertional mutagenesis in slowly turning over differentiated lung epithelium is unknown, but is likely to be lower than in rapidly dividing bone marrow cells. In addition, the improved design of self-inactivating lentiviral vectors has improved safety (21). Here we compared survival, weight, and lung histology during a 24-month study period and did not see any differences between F/HN-SIV- and PBS-treated mice. We included only female mice in the study because they can be more readily housed together for prolonged periods of time. It is unlikely that the toxicology profile in male mice would be significantly different. However, before progression into clinical trial a good laboratory practice (GLP)-toxicology study, including male and female animals and dose-ranging, has to be performed. Despite the encouraging toxicology profile of our current vector configuration we plan to assess further modifications before final vector selection for clinical trials, including the use of mammalian promoters and ubiquitous chromatin opening elements. The former have been shown to reduce the risk of insertional mutagenesis compared with strong viral promoters (22), whereas the latter may reduce gene silencing (22). The ability to administer 
this vector repeatedly and efficiently also opens the possibility of using nonintegrating lentiviral vectors (23), which may further reduce the genotoxic risk.

As part of our translational pathway we next determined whether $\mathrm{F} / \mathrm{HN}-\mathrm{SIV}$ is able to transduce human tissues. We have previously shown that F/HN-SIV can transduce fully differentiated human ALI cultures when analyzed 5 days after transduction (11). These cultures mimic human airway epithelium and are difficult to transfect (24). Here, we have extended these studies and show that F/HNSIV-mediated expression in ALIs is stable; persists for at least 3 months (the length of the experiment); and is higher than GL67Amediated expression, which in our hands is currently the most efficient nonviral vector. Preliminary experiments indicated that in contrast to lipid-mediated gene transfer, F/HN-SIV does not seem to damage the ALI cultures, but more extensive studies are required to determine acute toxicity in vitro and in vivo.

To further evaluate the viral vector in even more relevant tissues we assessed freshly obtained human primary airway cells and showed that F/HN-SIV-Lux transduction leads to significant levels of luciferase expression. We performed only short-term $(24 \mathrm{~h})$ experiments to avoid potential cell division, which would have affected interpretation of the results. Collection of primary cells by nasal brushings exposes the basolateral membrane of these cells and we cannot exclude the possibility that the vector may have entered the cells by this route. However, experiments performed in mice in vivo and in ALI cultures clearly show that F/HN-SIV can transduce airway epithelial cells when applied to the apical membrane without the need to coadminister agents to open tight junctions. There was no difference in gene expression when cells were transduced with an MOI of 25 or 250. In future experiments the MOI will be further reduced to determine the minimum MOI for efficient transduction.

We also assessed F/HN-SIV in precision-cut human lung slices. Expression in both experiments was stable and persisted for at least 14 days, after which the experiment was terminated because of reduced tissue viability. Although we have not determined which cells express the recombinant protein these studies show that persistent SIV-mediated transduction into human pulmonary cells is feasible and is not prevented by viral restriction factors. We also transduced ovine lung slices, which are generally more resilient when cultured (Nikki Newman, personal communication); stable luciferase expression was detectable for at least 26 days. These data support the future use of these models in the clinical development of this vector.

$\mathrm{SeV}$ shares high sequence homology with human parainfluenza virus and preexisting immunity may be a factor. Interestingly, Slobod and coworkers (25) assessed SeV-vaccination against human parainfluenza virus and reported evidence of immunogenicity in three of nine vaccinees despite preexisting, cross-reactive immunity presumably induced by previous exposure to human parainfluenza virus-1. Although this initial study is encouraging, the effects of preexisting humoral immunity on virus transduction efficiency is something we will address as a high priority.

Gene transfer to the airway epithelium is more difficult than originally anticipated. Until now viral gene transfer agents have not been useful for the treatment of chronic lung disease, such as $\mathrm{CF}$, because of immunogenicity, which prevents successful repeat administration. Lentivirus-based vectors are a notable exception. Moving novel therapies to the clinic requires that relevant evidence for safety and efficacy is gathered in appropriate models. Here, we begin to place this vector onto a translational pathway to the clinic and provide a body of supportive evidence for F/HN-pseudotyped SIV as a potential gene transfer agent for $\mathrm{CF}$ including (1) lifetime gene expression and efficient repeat administration in mouse lung, (2) lack of chronic toxicity, and (3) persistent gene expression in human ex vivo models.
The data presented here support F/HN-SIV as a promising vector for pulmonary gene therapy, with potential for many diseases including CF. We are currently undertaking the next critical steps (vector optimization and virus production) in this developmental process toward clinical evaluation and are improving vector optimization and viral production methods to support progression into early phase trials.

Author disclosures are available with the text of this article at www.atsjournals.org. Acknowledgment: The authors thank Lucinda Hellings and Samia Soussi for help with preparing the manuscript.

\section{References}

1. Griesenbach U, Alton EW. Progress in gene and cell therapy for cystic fibrosis lung disease. Curr Pharm Des 2012;18:642-662.

2. Yonemitsu Y, Kitson C, Ferrari S, Farley R, Griesenbach U, Judd D, Steel R, Scheid P, Zhu J, Jeffery PK, et al. Efficient gene transfer to airway epithelium using recombinant Sendai virus. Nat Biotechnol 2000;18:970-973.

3. Griesenbach U, Cassady RL, Ferrari S, Fukumura M, Muller C, Schmitt E, Zhu J, Jeffery PK, Nagai Y, Geddes DM, et al. The nasal epithelium as a factory for systemic protein delivery. Mol Ther 2002;5:98-103.

4. Harvey BG, Leopold PL, Hackett NR, Grasso TM, Williams PM, Tucker AL, Kaner RJ, Ferris B, Gonda I, Sweeney TD, et al. Airway epithelial CFTR mRNA expression in cystic fibrosis patients after repetitive administration of a recombinant adenovirus. J Clin Invest 1999;104:1245-1255.

5. Sumner-Jones SG, Davies LA, Varathalingam A, Gill DR, Hyde SC. Long-term persistence of gene expression from adeno-associated virus serotype 5 in the mouse airways. Gene Ther 2006;13:1703-1713.

6. Limberis M, Anson DS, Fuller M, Parsons DW. Recovery of airway cystic fibrosis transmembrane conductance regulator function in mice with cystic fibrosis after single-dose lentivirus-mediated gene transfer. Hum Gene Ther 2002;13:1961-1970.

7. Cmielewski P, Anson DS, Parsons DW. Lysophosphatidylcholine as an adjuvant for lentiviral vector mediated gene transfer to airway epithelium: effect of ACYL chain length. Respir Res 2010;11:84.

8. Medina MF, Kobinger GP, Rux J, Gasmi M, Looney DJ, Bates P, Wilson JM. Lentiviral vectors pseudotyped with minimal filovirus envelopes increased gene transfer in murine lung. Mol Ther 2003;8:777-789.

9. McKay T, Patel M, Pickles RJ, Johnson LG, Olsen JC. Influenza M2 envelope protein augments avian influenza hemagglutinin pseudotyping of lentiviral vectors. Gene Ther 2006;13:715-724.

10. Sinn PL, Arias AC, Brogden KA, McCray PB Jr. Lentivirus vector can be readministered to nasal epithelia without blocking immune responses. J Virol 2008;82:10684-10692.

11. Mitomo K, Griesenbach U, Inoue M, Somerton L, Meng C, Akiba E, Tabata T, Ueda Y, Frankel GM, Farley R, et al. Toward gene therapy for cystic fibrosis using a lentivirus pseudotyped with Sendai virus envelopes. Mol Ther 2010;18:1173-1182.

12. Kobayashi M, Iida A, Ueda Y, Hasegawa M. Pseudotyped lentivirus vectors derived from simian immunodeficiency virus SIVagm with envelope glycoproteins from paramyxovirus. J Virol 2003;77:2607-2614.

13. Rawlins EL, Hogan BL. Ciliated epithelial cell lifespan in the mouse trachea and lung. Am J Physiol Lung Cell Mol Physiol 2008;295:L231-L234.

14. Ohmori K, Takeda S, Miyoshi S, Minami M, Nakane S, Ohta M, Sawa Y, Matsuda H. Application of HVJ-liposome mediated gene transfer in lung transplantation-distribution and transfection efficiency in the lung. Eur J Cardiothorac Surg 2005;27:768-773.

15. Xenariou S, Griesenbach U, Liang HD, Zhu J, Farley R, Somerton L, Singh C, Jeffery PK, Ferrari S, Scheule RK, et al. Use of ultrasound to enhance nonviral lung gene transfer in vivo. Gene Ther 2007;14:768-774.

16. Griesenbach U, Meng C, Farley R, Gardner A, Brake MA, Frankel GM, Gruenert DC, Cheng SH, Scheule RK, Alton EW. The role of doxorubicin in non-viral gene transfer in the lung. Biomaterials 2009; 30:1971-1977.

17. Griesenbach U, Boyton RJ, Somerton L, Garcia SE, Ferrari S, Owaki T, Ya-Fen Z, Geddes DM, Hasegawa M, Altmann DM, et al. Effect of tolerance induction to immunodominant $\mathrm{T}$-cell epitopes of Sendai 
virus on gene expression following repeat administration to lung. Gene Ther 2006;13:449-456.

18. Hirayama S, Sato M, Liu M, Loisel-Meyer S, Yeung JC, Wagnetz D, Cypel M, Zehong G, Medin JA, Keshavjee S. Local long-term expression of lentivirally delivered IL-10 in the lung attenuates obliteration of intrapulmonary allograft airways. Hum Gene Ther 2011;22: 1453-1460.

19. Wilson AA, Murphy GJ, Hamakawa H, Kwok LW, Srinivasan S, Hovav AH, Mulligan RC, Amar S, Suki B, Kotton DN. Amelioration of emphysema in mice through lentiviral transduction of long-lived pulmonary alveolar macrophages. $J$ Clin Invest 2010;120:379-389.

20. Griesenbach U, Meng C, Farley R, Wasowicz MY, Munkonge FM, Chan M, Stoneham C, Sumner-Jones SG, Pringle IA, Gill DR, et al. The use of carboxymethylcellulose gel to increase non-viral gene transfer in mouse airways. Biomaterials 2010;31:2665-2672.
21. Booth C, Gaspar HB, Thrasher AJ. Gene therapy for primary immunodeficiency. Curr Opin Pediatr 2011;23:659-666.

22. Mukherjee S, Thrasher AJ. Progress and prospects: advancements in retroviral vector design, generation, and application. Hum Gene Ther 2011;22:1171-1174.

23. Banasik MB, McCray PB Jr. Integrase-defective lentiviral vectors: progress and applications. Gene Ther 2010;17:150-157.

24. Griesenbach U, Vicente CC, Roberts MJ, Meng C, Soussi S, Xenariou S, Tennant P, Baker A, Baker E, Gordon C, et al. Secreted Gaussia luciferase as a sensitive reporter gene for in vivo and ex vivo studies of airway gene transfer. Biomaterials 2011;32:2614-2624.

25. Slobod KS, Shenep JL, Lujan-Zilbermann J, Allison K, Brown B, Scroggs RA, Portner A, Coleclough C, Hurwitz JL. Safety and immunogenicity of intranasal murine parainfluenza virus type 1 (Sendai virus) in healthy human adults. Vaccine 2004;22:3182-3186. 